\title{
INVESTIGATION OF AN OUTBREAK OF GASTROENTERITIS ON A CONTAINER SHIP RETURNING FROM ASIA
}

Leena Gupta and Bernie Towler, Eastern Sydney Public Health Unit Michael Frommer, Public Health Division, NSW Health Department

This article describes action taken when the NSW Health Department responded to a notification by the Australian Quarantine Inspection Service (AQIS) that 13 crew members on an Australian container ship, due to dock at Port Botany, had been unwell with a diarrhoeal illness. The ship had travelled to Asia and the notification was received four days before it was due to berth in Sydney on its return trip. The ship's master was concerned that crew members had become ill after docking in Taiwan, 19 days before their arrival in Sydney.

Following contact with the shipping line, arrangements were made for staff from the Eastern Sydney Public Health Unit and the Epidemiology Branch to investigate the possibility of an outbreak of foodborne or waterborne illness, institute any public health or quarantine measures necessary to minimise further spread of infection and prevent recurrence of similar outbreaks on the ship. The aims of the investigation were to:

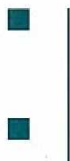

ascertain whether any affected crew members had a quarantinable illness requiring isolation or medical attention; and identify the source of infection and/or any shipboard practices that might have favoured its spread.

One member of the team (MF) had authority under the Commonwealth Quarantine Act 1909 to conduct this investigation.

\section{BACKGROUND}

The ship's company and its itinerary

The ship was a cargo container vessel with a company of 20 Australian males. The ship had left Brisbane four weeks previously. The itinerary included the following ports (in order): Yokohama, Yokkaichi, Nagoya, Osaka, Keelung (Taiwan) and Hong Kong. All crew members had boarded the ship at Brisbane and remained as part of the company until arrival in Sydney. No additional crew were taken aboard at other ports.

When the ship entered Port Botany, it was flying the yellow quarantine flag, signalling illness on board. Crew disembarkation and unloading of cargo could not begin until the ship had been cleared by the investigation team. There was considerable pressure to complete the investigation as soon as possible because of the commercial imperative to unload cargo, and because many crew members were due to leave the ship after completing a tour of duty of several weeks' duration.

\section{Facilities}

Food sources and preparation

A set menu was prepared on the ship daily by the same two crew members. Crew members could eat whatever they wished from the food stores at any time. All packaged foods and most fresh food had been bought in Australia. Some perishables were obtained, from each of the overseas ports, as required. Fresh vegetables and fruit were obtained on this trip at Keelung, Taiwan. When on shore, the men generally ate main meals prepared on the ship.

\section{Water supply}

Only desalinated water was used on the ship for drinking and washing. Desalination was the only treatment for the drinking water. Ice was made in a machine using stored desalinated water.

\section{Living quarters}

Each crew member had separate living quarters with individual toilet facilities.

\section{Ballast water}

Before docking, the Water Board was asked about the appropriate procedure for discharge of ballast water, because of the potential for transporting contaminated ballast water from other waters to Sydney Harbour. The Water Board advised that ballast water was routinely discharged into Sydney's sewerage system and treated. As ballast water did not pose a health threat, it was discharged into Sydney's sewerage system before docking.

\section{INVESTIGATION METHODS}

Brief details such as number of cases, approximate onset dates, itinerary and condition of cases were obtained from the ship, through the shipping agent, in the three days before docking. Upon docking, investigators administered a verbal questionnaire to each crew member. Based on the histories, a case definition was defined as the presence of diarrhoea (loose or frequent stools). As the peak onset of illness was found to be two weeks before interview, no accurate food history could be obtained. As all cases were asymptomatic at the time of interview, detailed questioning about each meal was also considered unnecessary.

An immediate decision was made by the interviewers about whether each crew member had a quarantinable illness or required immediate medical attention. Stool specimens were obtained from three of four cases whose diarrhoea had ceased in the 48 hours before interview. These were sent to the Institute of Clinical Pathology and Medical Research, Westmead Hospital, which deals with all quarantine specimens.

Menus, food preparation and storage facilities, living quarters and water desalination facilities were inspected. The chef was interviewed about food preparation and hygiene in the galley. Specimens of vegetables and milk were sent to the Division of Analytical Laboratories for culture. The general level of hygiene on the ship was assessed and specimens of stored water were taken.

\section{RESULTS}

Results of the questionnaire were analysed using Epi-Info version 5 . The 20 crew members were all males, with an age range of 19-63 years and an average age of 40 years. All crew members were well at the time of boarding.

There were 16 cases of diarrhoea, all cases lasting at least 24 hours. The case attack rate was 80 per cent. Two other crew members had other gastrointestinal symptoms during the trip which were likely to be unrelated to the diarrhoeal 


\section{Gastroenteritis investigation}

Continued from page 61

\section{TABLE 1}

FREQUENCY OF REPORTED SYMPTOMS

\begin{tabular}{|lll|}
\hline Symptom & $\begin{array}{l}\text { Number of } \\
\text { cases }\end{array}$ & $\begin{array}{l}\% \text { of company } \\
\text { affected }\end{array}$ \\
\hline Diarrhoea & 16 & 80 \\
Abdominal cramps & 10 & 50 \\
Nausea & 8 & 40 \\
Fever & 7 & 35 \\
Headache & 6 & 30 \\
Vomiting & 5 & 20 \\
Abdominal pain & 1 & 5 \\
Sore throat & 1 & 5 \\
\hline
\end{tabular}

outbreak, as the symptoms were non-specific and/or of short duration (for example, one episode of vomiting, slight change in bowel habits). The frequency of reported symptoms for the 16 cases is outlined in Table 1.

The onset of the first case occurred 24 hours after the ship had left Taiwan. The peak incidence of cases occurred two days after the ship left Taiwan (Figure 2). At the time of interview, all men said they had fully recovered. However, one crew member had had diarrhoea until the previous day. On inspection of the facilities, it was considered that the standard of hygiene, particularly in food preparation, was adequate. All cultures of stool, food and water were negative.

\section{DISCUSSION}

The history given by the company suggested that an outbreak of a foodborne or waterborne illness had occurred on the ship. After preliminary investigation, we decided that crew members were unlikely to be infectious at the time of docking, as the illness appeared to have been self-limiting. The history given in all cases was not suggestive of cholera nor of any other quarantinable illness.

As a detailed food history was not taken, no point source of foodborne or waterborne illness was identified. The ship's master considered the source was vegetables bought in Taiwan, as the outbreak occurred within 24 hours of docking at Keelung. Specific questioning was therefore directed to procedures for washing fruit and vegetables, and utensils used in preparation of vegetables. These procedures were considered adequate. The potential for transmission of waterborne infection from the ice machine was considered, but could not be confirmed.

\section{PUBLIC HEALTH ACTION}

The attending AQIS officer was informed that crew members did not have a quarantinable illness, and the investigation team authorised crew members to disembark or begin unloading cargo. The yellow quarantine flag was lowered.

\section{FIGURE 2}

EPIDEMIC CURVE

OUTBREAK OF DIARRHOEAL ILLNESS

ON A CONTAINER SHIP

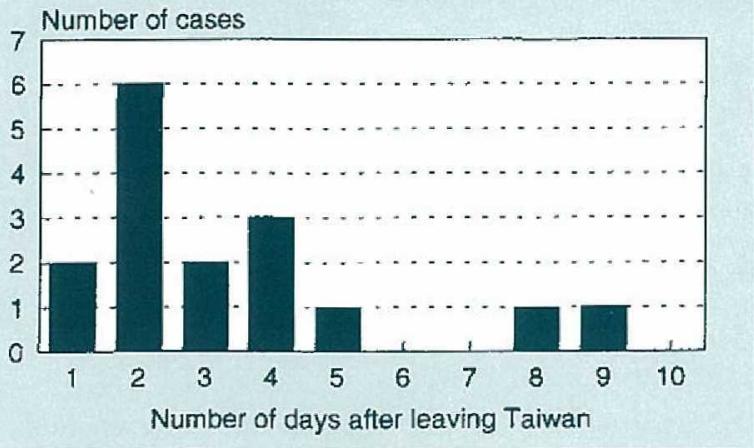

The investigation team requested that all provisions obtained overseas (comprising fresh vegetables and fruit) be placed into quarantine bins for destruction, and that water tanks be emptied. An information sheet was provided to the company with contact numbers, should they become ill. Advice about avoidance of foodborne and waterborne illness was given, such as preventing transmission by ice-making facilities or inadequately washed uncooked vegetables or fruit.

\section{CONCLUSION}

While the investigation of an outbreak of diarrhoeal illness on a container ship arriving from overseas was an unusual occurrence, the potential for further occurrences exists. The extent to which outbreaks of gastroenteritis or other illness occurs on ships such as these, and are not notified to quarantine authorities, is unknown.

We could not positively identify a causative organism from stool, food or water samples, and the most likely diagnosis was that of a viral food or waterborne illness. However, because of the potential for the transmission of a quarantinable illness, a thorough investigation was considered necessary, despite the subsequent negative microbiological findings.

Because of the need to detain all crew members aboard a ship until a preliminary investigation is complete, rapid investigation and clinical decision-making is required in outbreak investigations on ships or aircraft. Guidelines prepared by the US Centers for Disease Control, in addition to the methods and questionnaires used in this investigation, may assist in investigations of this nature in the future.

\section{ACKNOWLEDGMENT}

The authors acknowledge the assistance of Trudi Coutts, Paul Paraskevopoulos, Greg Thomas and Kerry Chant in this investigation. 